DOI: https://doi.org/10.24867/08EF04Todoric

\title{
UTICAJ KALIBRACIJE NA KRATKOROČNU PONOVLJIVOST I PROMENU RAZLIKE U BOJI U ELEKTROFOTOGRAFIJI
}

\section{THE EFFECT OF CALIBRATION ON SHORT-TERM REPEATABILITY AND COLOR DIFFERENCES IN ELECTROPHOTOGRAPHY}

\author{
Tamara Todorić, Sandra Dedijer, Fakultet tehničkih nauka, Novi Sad
}

\begin{abstract}
Oblast - GRAFIČKO INŽENJERSTVO I DIZAJN
Kratak sadržaj - Cilj svake tehnike štampe, jeste dobijanje kvalitetnog i postojanog otiska, tačna reprodukcija boje i moguća ponovljivost štampe. Cilj ovog rada jeste testiranje uticaja procesa kalibracije na kratkoročnu ponovljivost štampe, $i$ analizu reprodukovane razlike $u$ boji, i kako na sve to utiče štamparski postupak elektrofotografije. Vrednosti razlike u boji su unapred definisane promenom vrednosti svetline. Hromatske koordinate a $i b$ su ostale nepromenjene. Tri seta tabaka su ispitivana, jedan gdje je kalibracija vršena pre svakog štampanja, drugi gde je kalibracija vršena samo prvog dana $i$ treći gde kalibracija nije vršena niti u jednom vremenskom trenutku.
\end{abstract}

Ključne reči: Kalibracija, razlika u boji, elektrofotografija, Lab vrednosti

Abstract - The goal of every printing technique is to get a high quality, durable print, accurate color reproduction and possible repeatability. The aim of this paper is to test the influence of the calibration process on the short-term repeatability of the print, and to analyze the reproduced color difference, and how all this is affected by the printing process of electrophotography. The color difference values are predefined by changing the brightness value. The chromatic coordinates $a$ and $b$ remained unchanged. Three sets of sheets were examined, the one where the calibration of the machine was done before printing of each sheet, the seconf where the calibration was the the first day of printing and third, where the alibration was completely ommited.

Keywords: Calibration, color difference, electrophotography, Lab values

\section{UVOD}

Elektrofotografija je jedna od glavnih tehnika digitalne štampe. Proces elektrofotografije se sastoji iz 5 faza. To su oslikavanje, obojavanje, prenos tonera, fikisiranje tonera i kondicioniranje [1].

Cilj je postići najkvalitetniji otisak. Kontrola kvaliteta započinje još sa obukom zaposlenih i njihovim iskustvom, sa određivanjem parametara štampe, proverom i merenjima. Atributi kvaliteta štampe su boja, svetlina, kontrast, oštrina, nepravilnosti i fizički atributi [2].

\section{NAPOMENA:}

Ovaj rad proistekao je iz master rada čiji mentor je bila dr Sandra Dedijer, vanredni profesor.
Kalibracija je važan korak u procesu štampe. Ona omogućava ponovljivu i stabilnu reprodukciju. Podešava se prema zahtevima relevantnog standarda ili konkretnog procesa. Kalibracija vrši linearizaciju uređaja. Kalibracija se procenjuje štampom test karti sa neutralnim poljima $\mathrm{i}$ merenjem CIE Lab vrednosti. Procena može da se vrši i vizuelno [3].

Kvalitet otiska se odnosi i na ponovljivost u štampi. To je važan parametar, koji pokazuje koliko je sistem konzistentan i kolika su odstupanja između otisaka. Kod procesa digitalne štampe su baš ponovljivost $i$ održavanje kvaliteta najzahtevniji parametri. Razlog je nepostojanje fizičke štamparske forme, u odnosu na konvencionalne štamparske sisteme [4].

Postoje dve vrste ponovljivosti, kratkoročna i dugoročna ponovljivost. Prema preporukama programa za sertifikaciju IDEAlliance grupe, kratkoročna ponovljivost je zadovoljena, odnosno štampa se smatra ponovljivom, ako su vrednosti $\Delta \mathrm{E}_{00} \leq 3$ između svih test polja.

\section{REZULTATI I DISKUSIJA}

Eksperimentalni deo rada se bavi uticajem kalibracije na kratkoročnu ponovljivost štampe i promenu razlike u boji u štamparskom postupku elektrofotografije.

Vrednosti razlike u boji su unapred definisane, promenom vrednosti svetline, dok su vrednosti hromatskih koordinata a i b ostale nepromenjene. Vršena su merenja za crvenu i sivu boju. Odštampana su tri seta tabaka, na mašini Xerox Versant 80. Prvi set sa delimičnom kalibracijom, odnosno kalibracijom na početku prvog dana štampanja, drugi set nije kalibrisan, a treći je potpuno kalibrisan, odnosno sa kalibracijom pre svakog vremenskog trenutka štampanja. U svakom setu deo tabaka je štampan u nultom času nakon kalibracije, deo je štampan nakon $1 \mathrm{~h}$, a deo nakon $24 \mathrm{~h}$ od prve štampe.

$\mathrm{Na}$ taj način se vrši provera kratkoročne ponovljivosti. Na tabacima se nalazi 25 polja sa promenjenim vrednostima svetline sa korakom od 0,5. Merenje vrednosti je vršeno sa spektrofotometrom I1 Basic Pro 2, standardno osvetljenje D50 i posmatrač 2 stepena. Spektrofotometar je kalibrisan na beloj pločici, a merenje je vršeno na crnoj podlozi. Vrednosti razlika u boji su računate formulom $\Delta E 00$. Vršena je analiza rezultata sa tri stanovišta. Prikazani su rezultati i analiza reprodukcije vrednosti svetline, rezultati razlike u boji i rezultati kratkoročne ponovljivosti štampe. 


\subsection{Analiza za crvenu boju}

2.1.1.Rezultati i analiza rezultata reprodukcije svetline Na slici 1 je predstavljen grafički prikaz apsolutne razlike u svetlini kod crvene boje, na početku prvog dana odnosno u Oh trenutku štampe. Posmatrajući grafikon vidimo da u delu gde se vrednost svetline smanjuje, odstupanja manja u odnosu na referentne vrednosti. U delu grafikona gde se vrednost svetline povećava, najveća odstupanja su dobijena sa setom koji nije uopšte kalibrisan i koji je u potpunosti kalibrisan. Najveća dobijena vrednost razlike u svetlini je 7,5 sa setom koji nije uopšte kalibrisan. Najbolji rezultati su dobijeni sa delimično kalibrisanim setom.

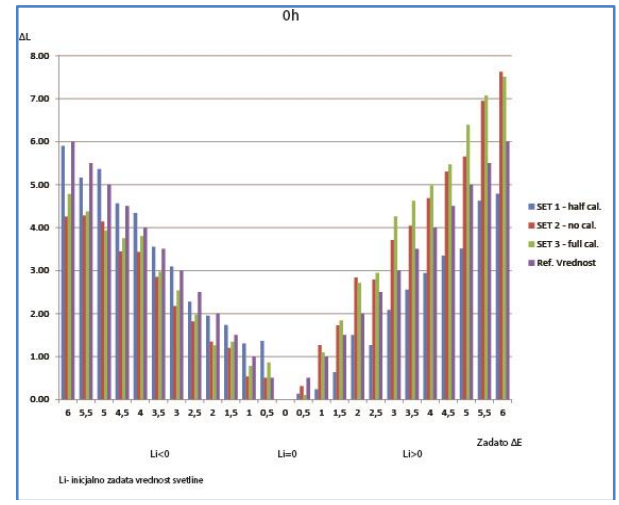

Slika 1. Grafički prikaz apsolutne razlike u svetlini za Oh

$\mathrm{Na}$ slici 2 je predstavljen grafički prikaz vrednosti apsolutne razlike u svetlini tabaka koji su odštampani nakon $1 \mathrm{~h}$. Manja odstupanja su dobijena u delu grafikona gde se vrednost svetline smanjuje i sva tri seta su dala približno slične rezultate. $U$ delu gde se vrednost svetline povećava, najbolji rezultati su dobijeni sa delimično kalibrisanim setom, kao što je slučaj i sa nultim časom štampe. Vrednost $\Delta$ L iznosi preko 7.

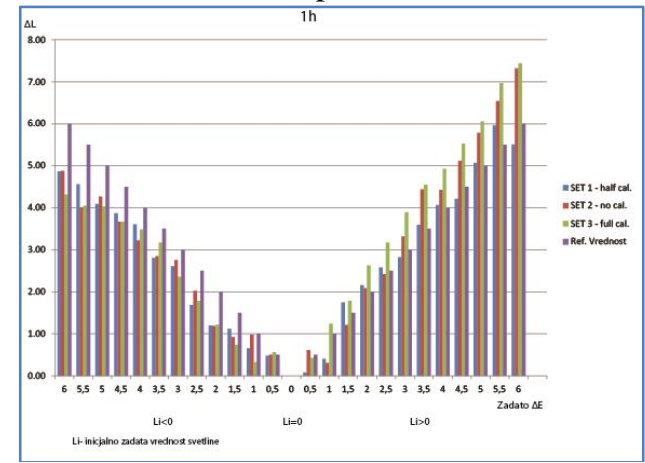

Slika 2. Grafički prikaz apsolutne razlike u svetlini za $1 \mathrm{~h}$

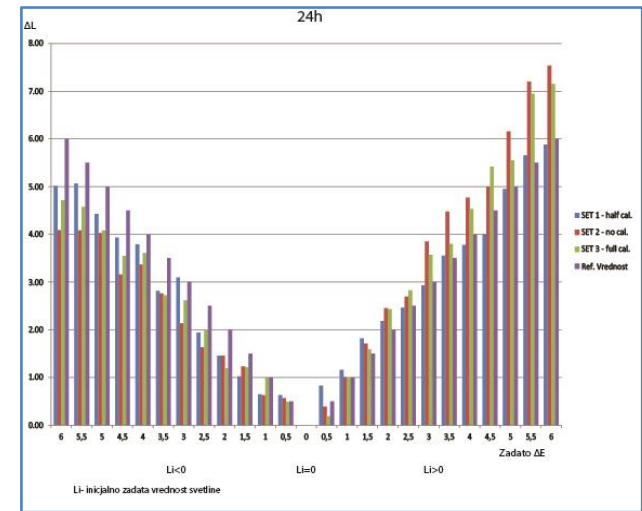

Slika 3. Grafički prikaz apsolutne razlike u svetlini za $24 \mathrm{~h}$
Na slici 3 je prikazan grafikon sa apsolutnim vrednostima razlike u svetlini $24 \mathrm{~h}$ nakon prve štampe. Kao i na prethodna dva grafikona, vidi se da su manja odstupanja u opsegu gde se vrednost svetline smanjuje. Najpribližniji rezultati referentnim su dobijeni sa delimično kalibrisanim setom. Vrednosti hromatskih koordinata nisu menjane, ali je ipak došlo do varijacija kod njih. Kod sva tri vremena štampe, veće su vrednosti dobijene kod hromatske koordinate $\mathrm{b}, \mathrm{u}$ odnosu na koordinatu a. Najmanje vrednosti su dobijene sa delimično kalibrisanim setom.

\subsubsection{Rezultati i analiza rezultata razlike u boji}

Na slikama 4, 5 i 6 su prikazane vrednosti apsolutnih razlika u boji za štampu na početku $(0 \mathrm{~h})$, nakon $1 \mathrm{~h}$ i nakon 24h. Sva tri seta su predstavljena na grafikonima. Primetna su odstupanja dobijenih vrednosti u odnosu na referentne.

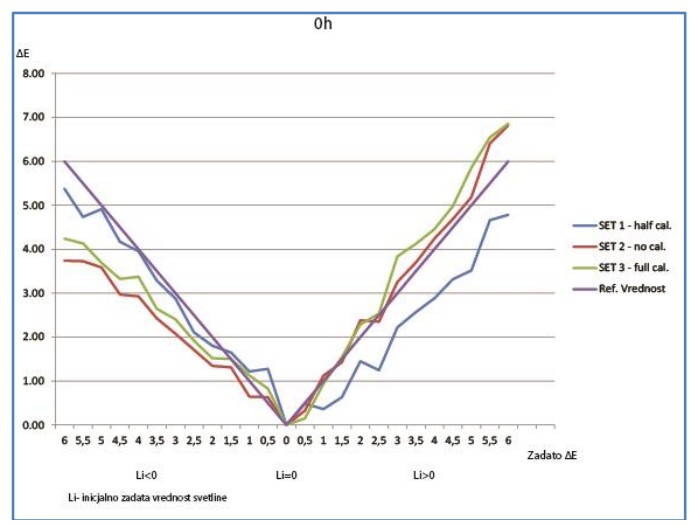

Slika 4. Grafički prikaz apsolutne razlike u boji za Oh

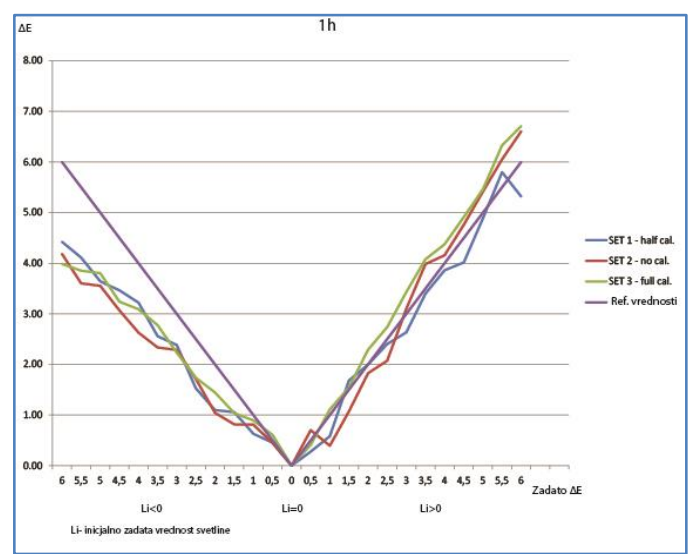

Slika 5. Grafički prikaz apsolutne razlike u boji za $1 \mathrm{~h}$

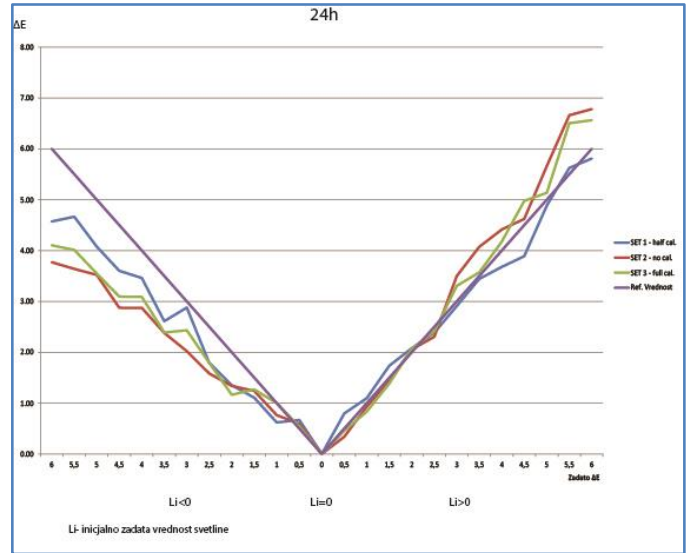

Slika 6. Grafički prikaz apsolutne razlike u boji za $24 \mathrm{~h}$ 
Na slici 4, gde su predstavljene vrednosti razlika u boji za nulti čas, najveća odstupanja su u opsegu od 4 do 6 zadate $\Delta \mathrm{E} \mathrm{u}$ delu gde se vrednost svetline povećava. Sa smanjenjem svetline, najpribližnije vrednosti referentnim dobijamo sa delimično kalibrisanim setom. Na slici 5, vrednosti bliže referentnim su dobijene u delu grafikona gde $\mathrm{Li}>0$. Sva tri seta su dala približno slične rezultate. U delu grafikona gde se smanjuje vrednost svetline, najlošije rezultate je dao set koji nije uopšte kalibrisan. Na slici 6 , gde su predstavljene razlike u boji za $24 \mathrm{~h}$ štampe, isti je slučaj kao sa prethodnim grafikonom, manja odstupanja su u delu povećanja vrednosti svetline. Najidealnije vrednosti su dobijene sa setom koji je delimično kalibrisan, kod sva tri vremena štampanja.

\subsubsection{Rezultati i analiza rezultata kratkoročne ponovljivosti}

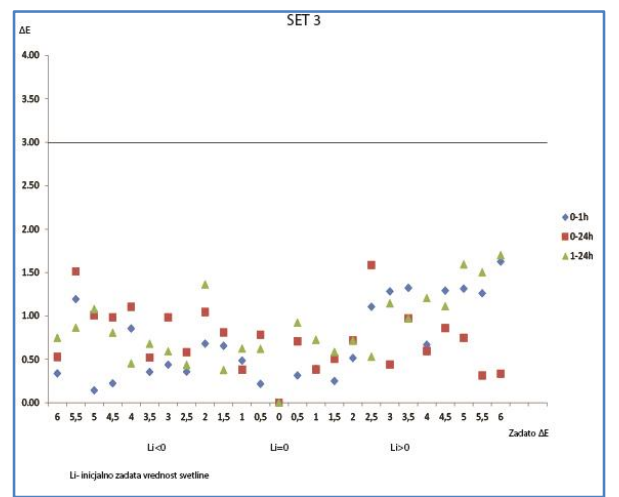

Slika 7. Graficki prikaz apsolutne razlike u boji za set 3

Grafik prikazan na slici 7 prikazuje da je kratkoročna ponovljivost štampe moguća. Vrednost razlike u boji od 3 je granica koju prema programu za sertifikaciju IDEAlliance grupe ne treba preći kako bi kratkoročna ponovljivost bila zadovoljavajuća. Na grafikonu je predstavljen set koji je potpuno kalibrisan. Maksimalna vrednost je do 1,75. Najveće razlike u boji su dobijene između 1 i $24 \mathrm{~h}$. Još manje razlike u boji su dobijene kod setova sa delimičnom kalibracijom kao i bez kalibracije.

\subsection{Analiza za sivu boju}

2.2.1.Rezultati i analiza rezultata reprodukcije svetline Na slikama 8, 9 i 10 je prikazana apsolutna vrednost razlike u svetlini kod sive boje. Kod nultog časa su minimalna odstupanja u delu smanjenja svetline. Set sa potpunom kalibracijom je dao najbolje rezultate. Vrednosti razlike u svetlini maksimalno iznose 6 , što je manje u odnosu na crvenu boju. Kod štampe nakon $1 \mathrm{~h}$, veća su odstupanja u odnosu na nulti nčas štampe.

Veća odstupanja su dobijena sa smanjenjem svetline. Delimično kalibrisan set je dao najpribližnije rezultate referentnim. Kod štampe nakon $24 \mathrm{~h}$, je sličan slučaj kao sa prethodna dva vremena štampe. Sa povećanjem vremena štampe, povećavaju se vrednosti odstupanja. Ta povećanja su minimalna. Najbolje rezultate je dao set sa delimičnom kalibracijom, kao u većini slučajeva. Kod hromatskih koordinata su primetne dobijene razlike, iako nisu inicijalno menjane njihove vrednosti. Kod hromatske koordinate a i hromatske koordinate $b$ vrednosti ne iznose iznad 1, za sva tri seta. Približni slične vrednosti su dobijene kod sva tri seta, međutim najmanje vrednosti su dobijene kod delimično kalibrisanog seta.

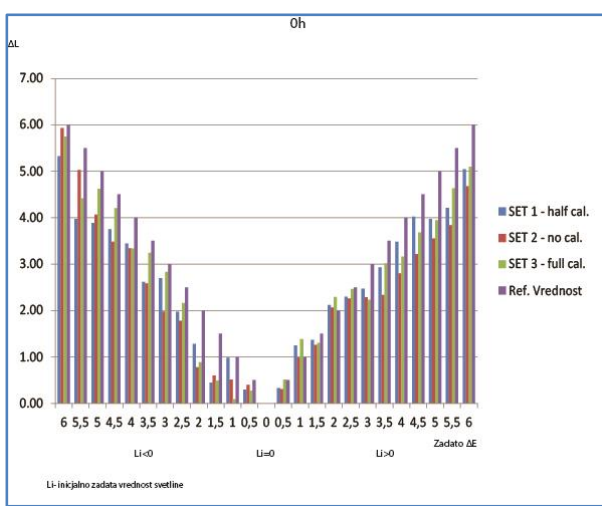

Slika 8. Grafički prikaz apsolutne razlike u svetlini za Oh

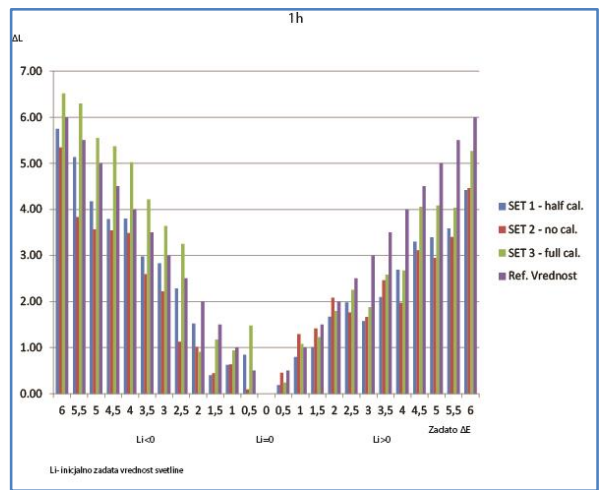

Slika 9. Grafički prikaz apsolutne razlike u svetlini za $1 \mathrm{~h}$

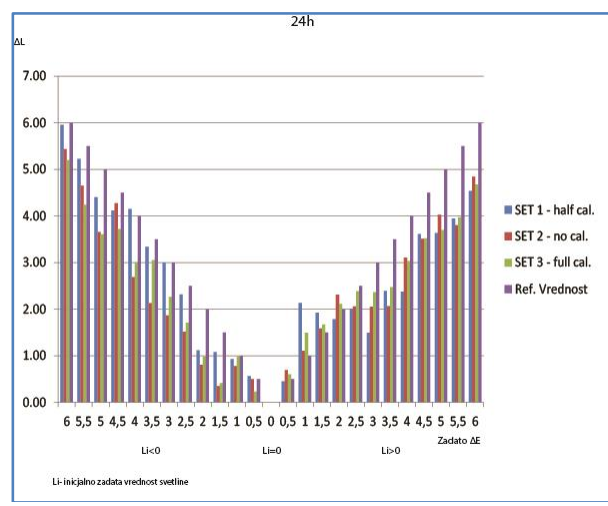

Slika 10. Grafički prikaz apsolutne razlike u svetlini za $24 h$

Poredeći koordinatu a i b, kod koordinate b su dobijene veće vrednosti. Veća su povećanja u delu grafikona gde se vrednost svetline smanjuje. U odnosu na crvenu, što se tiče hromatskih koordinata, manje su vrednosti kod sive.

\subsubsection{Rezultati i analiza rezultata razlike $u$ boji}

Na slikama 11, 12 i 13 su predstavljenje apsolutne vrednosti razlika u boji kod sive boje. Posmatrajući sva tri grafikona, najveće odstupanje se primeti kod štampe $1 \mathrm{~h}$ nakon prve štampe. Kod nultog časa štampe, veća su odstupanja u delu povećanja svetline. Kod štampe u prvom i dvadeset i četvrtom času, veća su odstupanja u delu smanjenja svetline.

Setovi sa delimičnom i potpunom kalibracijom daju najpribližnije rezultate referentnim. Vrednost $\Delta \mathrm{E}$ ne iznosi više od 6. 


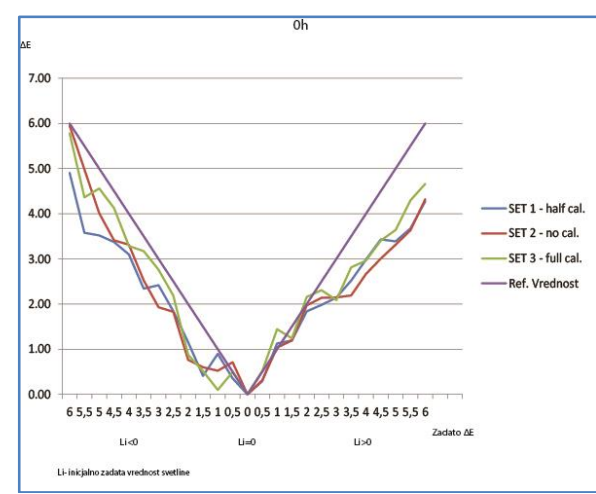

Slika 11. Grafički prikaz apsolutne razlike u boji za Oh

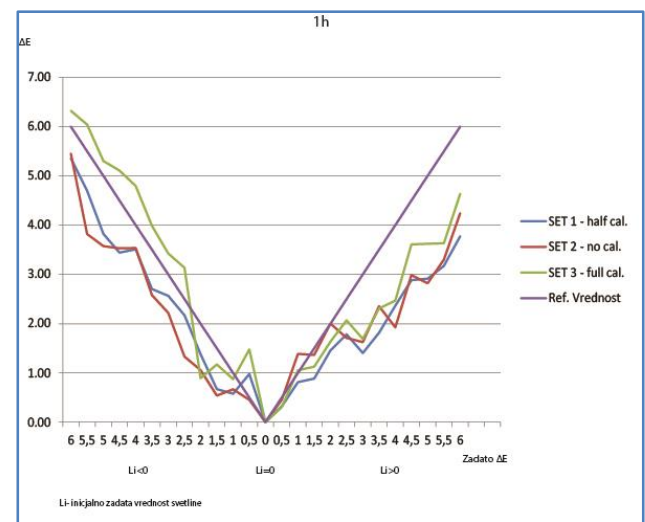

Slika 12. Grafički prikaz apsolutne razlike u boji za $1 \mathrm{~h}$

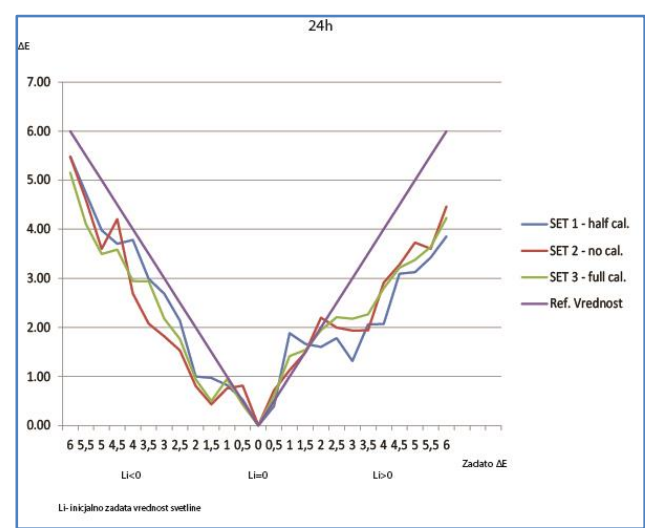

Slika 13. Grafički prikaz apsolutne razlike u boji za $24 \mathrm{~h}$

\subsubsection{Rezultati i analiza rezultata kratkoročne} ponovljivosti

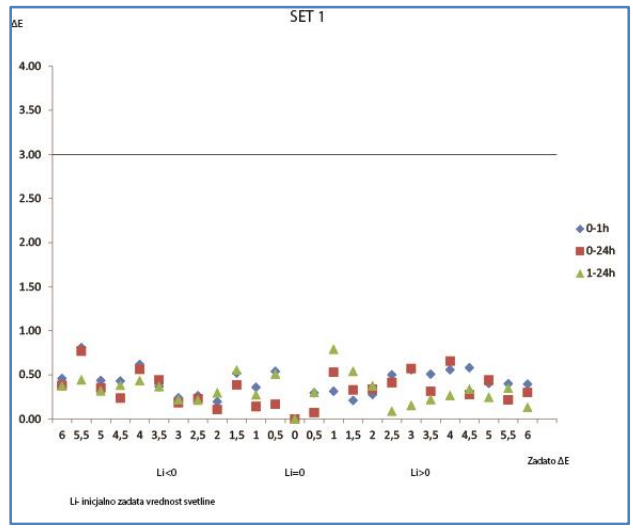

Slika 14. Grafički prikaz apsolutne razlike u boji za set 1
Na slici 14 je predstavljen grafik za set broj 1, odnosno delimično kalibrisan set. Predstavljena je razlika $\mathrm{u}$ boji između 0-1h, 0-24h i 1-24h. Vrednost ne iznosi više od 3, što znači da je štampa kratkoročno ponovljiva. Najmanje vrednosti razlike su između nultog i $24 \mathrm{~h}$, u delu smanjenja svetline. Najveće vrednosti su dobijene sa setom koji je potpuno kalibrisan. Delimično kalibrisan i potpuno kalibrisan set imaju manje vrednosti razlika u boji.

\section{ZAKLJUČAK}

Cilj rada jeste bila analiza uticaja kalibracije na kratkoročnu ponovljivost i reprodukciju razlike boje promenom vrednosti svetline, na otiscima dobijenim elektrofotografijom. Manja odstupanja su dobijena kod sive boje. Vrednosti svetline su inicijalno menjane na početku eksperimenta. Vrednosti hromatskih koordinata ostaju nepromenjene. Međutim, dolazi do varijacija i kod njih. Kod sva tri vremena štampe su odstupanja bila veća u delu gde se vrednost svetline povećava. Najbolji rezultati su dobijeni sa delimičnom kalibracijom. Najveće odstupanje je imao set bez kalibracije. Maksimalna vrednost apsoultne razlike u svetlini nije iznad 6 . Hromatske koordinate i kod jedne i druge boje su imale varijacije. Kod obe boje su veće vrednosti dobijene kod hromatske koordinate b. Kod sive boje su vrednosti hromatskih komponenti manje. Vrednosti apsolutnih razlika u boji variraju kod sva tri seta, kod obe boje. Manje razlike su dobijene kod sive boje. Kod crvene boje najpribližnije vrednosti referentnim je dao set sa delimičnom kalibracijom. Kod sive boje, to su setovi sa potpunom i delimičnom kalibracijom. Najveća odstupanja imaju setovi bez kalibracije. Unutar seta uglavnom su najmanje razlike u vrednosti između $1 \mathrm{~h}$ i 24h štampe. Ni u jednom setu vrednost delta E nije preko 3 , što znači da je ponovljivost štampe moguća. Rezultati i analiza su pokazali da kalibracija ne utiče značajno na kratkorčnu ponovljivost u štampi, ali utiče na tačnost reprodukovanih razlika u boji. Prema rezultatima i analizi se ispostavilo da je delimična kalibracija pokazala najbolje rezultate $\mathrm{u}$ pogledu tačnosti reprodukcije razlike $\mathrm{u}$ boji i Lab vrednosti, a potpuna kalibracija na kratkoročnu ponovljivost štamparskih procesa.

\section{LITERATURA}

[1] Novaković, D., Kašiković, N.“ Digitalna štampa“, FTN Izdavaštvo, Novi Sad, 2013.

[2] Kašiković, N.,,Digitalna štampa“, Materijal sa vežbi, 2017. [Online] Dostupno na: http://www.grid.uns.ac.rs/storage/download.php?fajl= 0cd6a652ed1f7811192db1f700c8f0e7, (Pristupljenou oktobru 2019)

[3] Tomić, I. „Upravljanje bojama“, Materijal sa vežbi, 2018 [Online] Dostupno na: http://www.grid.uns.ac.rs/predmet2.html?predmet=83, (Pristupljeno u oktobru 2019)

[4] H. Kipphan, "Handbook of Printmedia". 1st Ed. Berlin, Springer, 2001.

\section{Kontakt:}

Tamara Todorić,todoricttamara@gmail.com Sandra Dedijer, dedijer@uns.ac.rs 